\title{
Remotely coupled surface plasmons in a two-colored plasmonic thermal emitter
}

\author{
Tzu-Hung Chuang, Ming-Wei Tsai, Yi-Tsung Chang, and Si-Chen Lee ${ }^{\text {a) }}$ \\ Department of Electrical Engineering, Graduate Institute of Electronics Engineering, National Taiwan \\ University, Taipei, Taiwan 106, Republic of China
}

(Received 15 July 2006; accepted 14 September 2006; published online 26 October 2006)

\begin{abstract}
A two-colored plasmonic thermal emitter is fabricated with a multilayer structure, in which the dielectric layers are sandwiched between two Ag films. The top Ag film is perforated periodically with holes in a squared array. The thermal radiation of the dielectric layer resonates between two metal films, and surface plasmon polaritons are induced on the top Ag film and then converted to light radiation. Furthermore, if the single dielectric layer is replaced with double layers, then an emission peak that corresponds to the remotely coupled surface plasmon is found in the plasmonic thermal emitter, and the coupling length is less than $500 \mathrm{~nm}$. (c) 2006 American Institute of Physics.
\end{abstract} [DOI: $10.1063 / 1.2370329$ ]

Extraordinary transmission, which is caused by the resonance of surface plasmons (SPs) through a periodic array of metal holes, has been reported. ${ }^{1,2}$ SPs are longitudinal waves that propagate along the surface of a conductor. Recently, many investigations on the dispersion relation of the surface plasmon polariton ${ }^{3-5}$ and time domain analysis ${ }^{6,7}$ have focused on the coupling mechanism of SPs with periodic structures. Extraordinary optical transmission in the middle and far infrared regions has also been demonstrated. ${ }^{8-11}$ The maximum transmission of a cascaded metallic structure, when a dielectric layer is sandwiched between two metal films, can exceed that of a corresponding single metallic structure by over $400 \% .^{12}$ Additionally, a narrow-band emitter has been demonstrated by applying the features of SPs. ${ }^{13}$ In this study, a two-colored plasmonic thermal emitter is fabricated using a cascaded metallic structure. When double dielectric layers, such as $\mathrm{SiO}_{2} / \mathrm{TiO}_{2}$, are deposited between two metal films, the $\mathrm{Ag} / \mathrm{TiO}_{2} \mathrm{SP}$ mode is established by coupling $\mathrm{Ag}$ and $\mathrm{TiO}_{2}$ across the $\mathrm{SiO}_{2}$ thin film in the middle infrared region. This mode is called a remotely coupled surface plasmon (RCSP) mode. ${ }^{14}$ Additionally, when the $\mathrm{SiO}_{2}$ thickness exceeds the coupling length of the $\mathrm{Ag} / \mathrm{TiO}_{2} \mathrm{RCSP}$ mode, this RCSP mode simply vanishes.

Double metal films that consist of a $50 \mathrm{~nm}$ layer of $\mathrm{Cr}$ followed by $100 \mathrm{~nm} \mathrm{Au}$ are thermally evaporated on the back of the double-polished Si substrate as a heating source. A 100-nm-thick Ag film with very low emissivity is deposited on the front side of the Si substrate to retard the substrate radiation; then, a 100 -nm-thick $\mathrm{SiO}_{2}$ or $\mathrm{TiO}_{2}$ insulator layer or $\mathrm{SiO}_{2} / \mathrm{TiO}_{2}$ double layers are deposited on the top of the Ag film. Then, another 100-nm-thick Ag metal film is deposited on the insulator layer and perforated with an array of squared holes by photolithography with a lattice constant $a$ of $3 \mu \mathrm{m}$ and a side length $L$ of the holes of $2 \mu \mathrm{m}$. The insets in Figs. 1 and 3 display side views of the devices. The inset of Fig. 1(a) presents the top view of the device. A Perkin Elmer 2000 fourier transform infrared spectrometer (FTIR) system is adopted to measure the thermal radiation spectra. Then, a dc current is sent into the back metal contact and heats up the sample. A thermocouple is put on the top of

\footnotetext{
${ }^{a)}$ Electronic mail: sclee@cc.ee.ntu.edu.tw
}

the sample to measure the temperature. When the sample is heated, the thermal radiation from the sample passes through the $\mathrm{KBr}$ window and is reflected into the FTIR by an off-axis mirror. The irradiated area of the sample is $1 \mathrm{~cm}^{2}$. The wave number resolution of the measurement is $8 \mathrm{~cm}^{-1}$. The sample is defined to lie in the $(x, y)$ plane, and the light is incident in the $z$ direction.

The conservation of momentum of SPs is

$$
\mathbf{k}_{\mathrm{sp}}=\mathbf{k}_{x}+i \mathbf{G}_{x}+j \mathbf{G}_{y},
$$

where $\mathbf{k}_{\mathrm{sp}}$ is the wave vector of the surface plasmon

$$
\left|\mathbf{k}_{\mathrm{sp}}\right|=\frac{\omega}{c}\left(\frac{\varepsilon_{1} \varepsilon_{2}}{\varepsilon_{1}+\varepsilon_{2}}\right)^{1 / 2} .
$$

Here, $\mathbf{k}_{x}=\left|\mathbf{k}_{0}\right| \sin \theta,\left|\mathbf{k}_{0}\right|=2 \pi / \lambda$ is the wave vector of the incident radiation, $\lambda$ is the wave length in a vacuum, and $\theta$ is the angle between the incident radiation and the $z$ direction. $\mathbf{G}_{x}$ and $\mathbf{G}_{y}$ are the reciprocal lattice vectors of a square lattice with $\left|\mathbf{G}_{x}\right|=\left|\mathbf{G}_{y}\right|=2 \pi / a$, where $a$ is the lattice constant, and $i$ and $j$ are integers. In Eq. (2), $\omega$ is the frequency of the SP that is excited by the incident radiation with the same frequency $\omega$, and $\varepsilon_{1}$ and $\varepsilon_{2}$ are the dielectric constants of the insulator and the metal, respectively. For normally incident light, $\mathbf{k}_{x}=0$, and Eq. (2) is reduced to

$$
\lambda=a\left(i^{2}+j^{2}\right)^{-1 / 2}\left(\frac{\varepsilon_{1} \varepsilon_{2}}{\varepsilon_{1}+\varepsilon_{2}}\right)^{1 / 2} .
$$

The real parts of the dielectric constant of $\mathrm{Ag}$ at 3,5 , and $6 \mu \mathrm{m}$ are $-1.31 \times 10^{3},-3.32 \times 10^{3}$, and $-1.44 \times 10^{4},{ }^{15}$ respectively. The dielectric constants of $\mathrm{SiO}_{2}$ and $\mathrm{TiO}_{2}$ at those wavelengths are 2.45 and 4.0. Therefore, theoretically, the degenerate $( \pm 1,0)$ and $(0, \pm 1)$ modes designated as $(1,0)$ $\mathrm{Ag} /$ air, $\mathrm{Ag} / \mathrm{SiO}_{2}$, and $\mathrm{Ag} / \mathrm{TiO}_{2} \mathrm{SP}$ modes are at 3, 4.7, and $6 \mu \mathrm{m}$ when the lattice constant of the hole arrays is $3 \mu \mathrm{m}$.

When the device is heated, the thermal radiation generated in the dielectric layer resonates between the two metal films, and the $\mathrm{Ag} / \mathrm{dielectric}$ and $\mathrm{Ag} /$ air surface plasmon polaritons are induced and then converted to light radiation. The emission spectra are measured at various temperatures from 200 to $300{ }^{\circ} \mathrm{C}$. Figure 1(a) shows the temperaturedependent emission spectra of device A with a single $\mathrm{SiO}_{2}$ intermediate layer, as shown in the inset. The thickness of the 

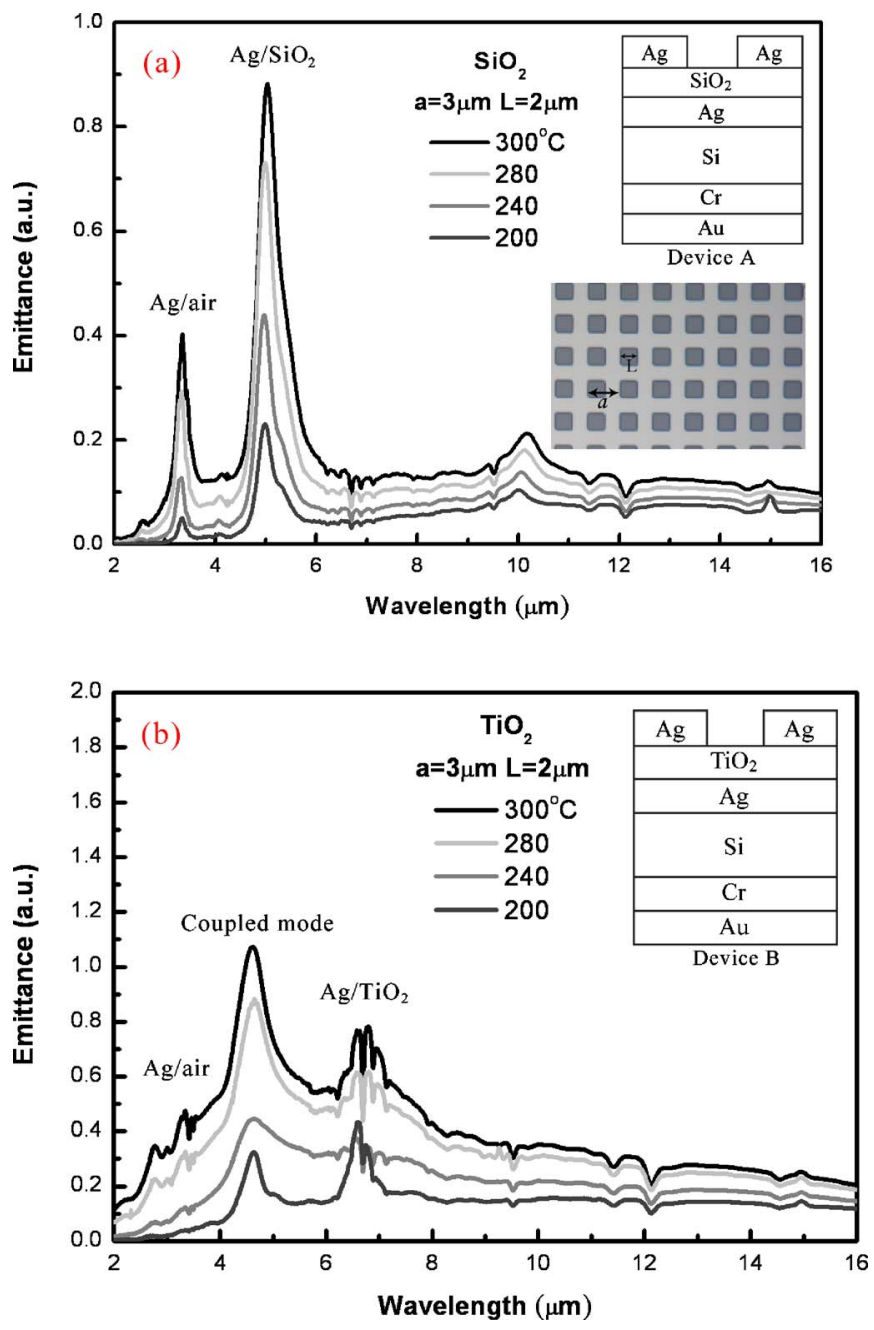

FIG. 1. (Color online) Emission spectra of devices (a) A and (b) B. Inset shows the structures of the devices. The hole array has a lattice constant $a$ of $3 \mu \mathrm{m}$, and the length of the sides of the square holes $L$ is $2 \mu \mathrm{m}$. The thickness of both the $\mathrm{SiO}_{2}$ and the $\mathrm{TiO}_{2}$ layers is $100 \mathrm{~nm}$.

$\mathrm{SiO}_{2}$ layer is $100 \mathrm{~nm}$. The spectra include two main peaks at 3.3 and $5.0 \mu \mathrm{m}$, which correspond to $\mathrm{Ag} / \mathrm{air}$ and $\mathrm{Ag} / \mathrm{SiO}_{2}$ $(1,0)$ degenerate SP modes, respectively. The emission peak around $10 \mu \mathrm{m}\left(1080 \mathrm{~cm}^{-1}\right)$ is attributed to the phonon vibration of the $\mathrm{SiO}_{2}$ layer. The emission peaks do not shift to shorter wavelength as the temperature increases, confirming that the radiation is from SPs and is not blackbody radiation. The bottom Ag film deposited on the front side of the $\mathrm{Si}$ substrate totally blocks the background radiation. The measured peak wavelength of the SP mode is slightly longer than the theoretical value because of the coupling of SPs between the bottom and top $\mathrm{Ag}$ films through the thin $\mathrm{SiO}_{2}$ layer. Additionally, a small peak at $4.1 \mu \mathrm{m}$ appears in Fig. 1(a), and corresponds to the cross coupling ${ }^{16}$ of the $\mathrm{Ag} / \mathrm{SiO}_{2}$ mode and the $\mathrm{Ag} /$ air mode. It becomes distinguishable in the thicker intermediate layer. Figure 1(b) displays the emission spectra of device $\mathrm{B}$ with a single $\mathrm{TiO}_{2}$ intermediate layer, as shown in the inset. The thickness of the $\mathrm{TiO}_{2}$ layer is $100 \mathrm{~nm}$, and its dielectric constant is 4.0. The spectra include two main peaks at 4.6 and $6.6 \mu \mathrm{m}$, which correspond to the cross coupling of $\mathrm{Ag} / \mathrm{air}$ with the $\mathrm{Ag} / \mathrm{TiO}_{2} \mathrm{SP}$ mode and the $(1,0)$ degenerate $\mathrm{Ag} / \mathrm{TiO}_{2} \mathrm{SP}$ mode, respectively. The strong $\mathrm{H}_{2} \mathrm{O}$ absorption at around 6.5 to $7 \mu \mathrm{m}$ causes the emission peak at $6.6 \mu \mathrm{m}$ to be not very sharp and the emittance to be Downloaded 04 Mar 2009 to 140.112.113.225. Redistribution subje

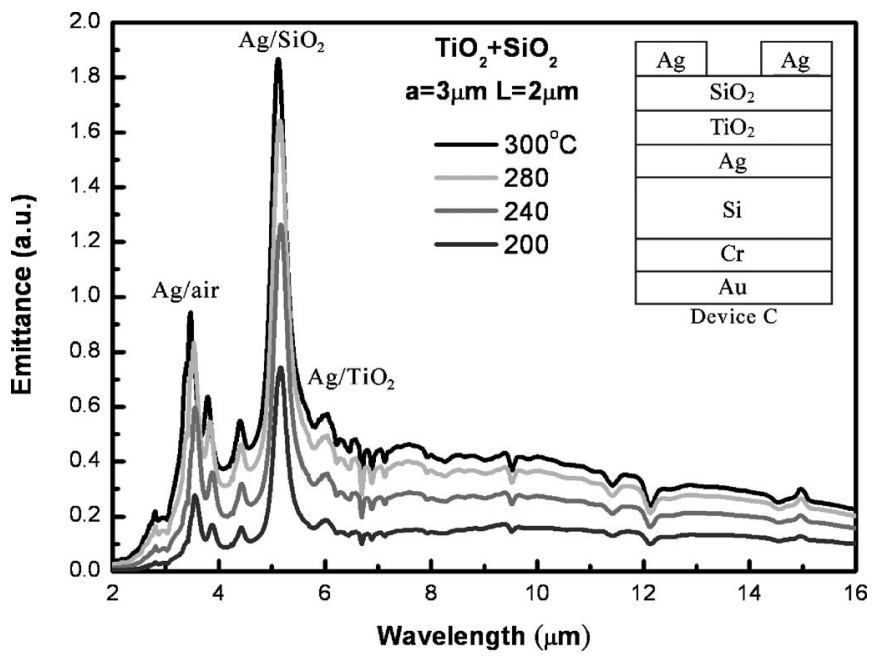

FIG. 2. Emission spectra of device $\mathrm{C}$ with $\mathrm{SiO}_{2} / \mathrm{TiO}_{2}$ double intermediate layers, as shown in the inset. The thickness of both the $\mathrm{TiO}_{2}$ and the $\mathrm{SiO}_{2}$ layers is $100 \mathrm{~nm}$.

weaker than that in the cross-coupled mode. The emission peaks of device B are broader than those of device A. Therefore, the Ag/air mode of device B seems to be weaker than that of device A. However, the ratio of the emittance of the
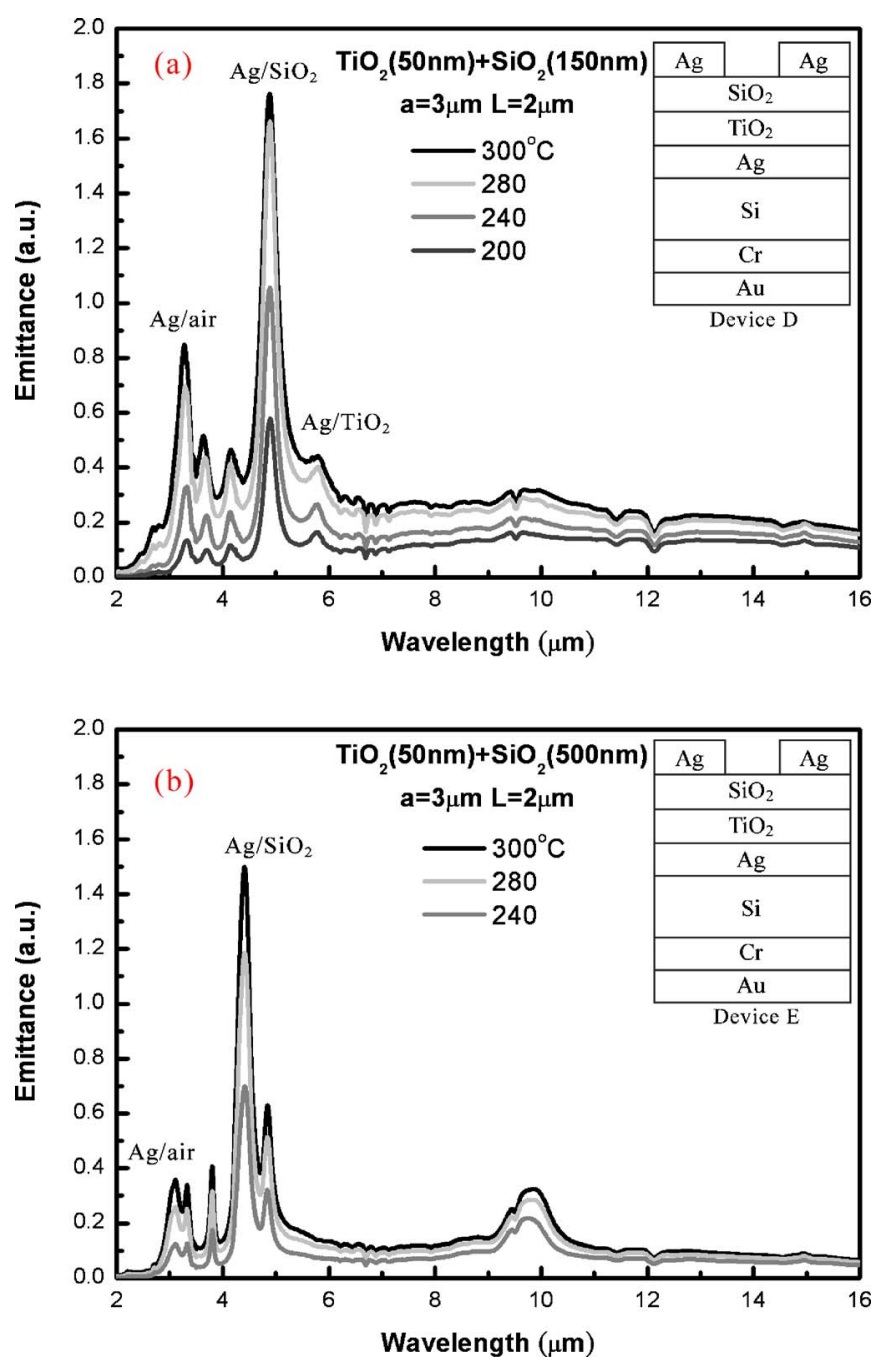

FIG. 3. (Color online) Emission spectra of device (a) D and (b) E with $\mathrm{TiO}_{2}$ and $\mathrm{SiO}_{2}$ double intermediate layers. The thickness of the $\mathrm{TiO}_{2}$ layer is

$50 \mathrm{~nm}$ and those of the $\mathrm{SiO}_{2}$ layers are (a) $150 \mathrm{~nm}$ and (b) $500 \mathrm{~nm}$.
to AIP license or copyright; see http://apl.aip.org/apl/copyright.jsp 
$\mathrm{Ag} / \mathrm{air}$ mode to that of the $\mathrm{Ag} /$ dielectric mode equals that of device A, as shown in Fig. 1(a).

Figure 2 shows the temperature-dependent emission spectra of device $\mathrm{C}$ with $\mathrm{SiO}_{2} / \mathrm{TiO}_{2}$ double layers, as shown in the inset. Both $\mathrm{TiO}_{2}$ and $\mathrm{SiO}_{2}$ layers are $100 \mathrm{~nm}$ thick. The spectra have five peaks at 3.5, 3.7, 4.3, 5.1, and $6.0 \mu \mathrm{m}$, which correspond to Ag/air $(1,0)$, the cross coupling of $\mathrm{Ag} /$ air with $\mathrm{Ag} / \mathrm{SiO}_{2}$, the cross coupling of $\mathrm{Ag} / \mathrm{air}$ with $\mathrm{Ag} / \mathrm{TiO}_{2}, \mathrm{Ag} / \mathrm{SiO}_{2}(1,0)$ degenerate, and $\mathrm{Ag} / \mathrm{TiO}_{2}(1,0)$ degenerate SP modes, respectively. Although a $\mathrm{SiO}_{2}$ layer is present between the $\mathrm{Ag}$ and $\mathrm{TiO}_{2}$ films, the $\mathrm{Ag} / \mathrm{TiO}_{2} \mathrm{SP}$ mode is clearly seen. The SP waves are not only excited at the interface between the metal and dielectric, but also remotely coupled to the other dielectric across the neighboring one. That is, collective charges on the metal surface induced by thermal radiation can remotely induce charges on the dielectric at a distance, satisfying the dispersion relation of the SP. Furthermore, in this double layer structure, the peak positions of each mode are all slightly redshifted with respect to those of the single layer structure because the coupling of SPs across a thicker intermediate layer is weaker.

Figure 3(a) shows the emission spectra of device D with a structure similar to that of device $\mathrm{C}$. The total thickness of the intermediate layer is the same, but the thicknesses of the $\mathrm{SiO}_{2}$ and $\mathrm{TiO}_{2}$ layers are 150 and $50 \mathrm{~nm}$, respectively. Each peak position is almost the same as shown in Fig. 2, and the $\mathrm{Ag} / \mathrm{TiO}_{2}$ RCSP modes at $5.7 \mu \mathrm{m}$ are still present. Figure 3(b) displays the emission spectra of device $\mathrm{E}$ with a similar structure, but with a $\mathrm{SiO}_{2}$ layer that is $500 \mathrm{~nm}$ thick. Clearly, the degenerate $(1,0) \mathrm{Ag} / \mathrm{TiO}_{2}$ and the cross coupling of $\mathrm{Ag} /$ air and $\mathrm{Ag} / \mathrm{TiO}_{2}$ modes all disappear. Therefore, the coupling length of the $\mathrm{Ag} / \mathrm{TiO}_{2} \mathrm{RCSP}$ mode in the plasmonic thermal emitter is less than $500 \mathrm{~nm}$. The remaining peaks are $\mathrm{Ag} / \mathrm{air}(1,0)$ modes at 3 and $3.2 \mu \mathrm{m}$, the $\mathrm{Ag} /$ air and $\mathrm{Ag} / \mathrm{SiO}_{2}$ cross coupling mode at $3.8 \mu \mathrm{m}$, and the $\mathrm{Ag} / \mathrm{SiO}_{2}(1,0)$ modes at 4.4 and $4.8 \mu \mathrm{m}$. The thicker intermediate layer splits the $(1,0)$ modes, which thus become more distinguishable and closer to the predicted positions. This is because the experiment is a far-field measurement. The emission solid angle collected in the system is about $30^{\circ}$. The different $(1,0)$ modes may emit in a slightly different emission angle with a different wavelength.

In summary, RCSPs in the plasmonic thermal emitter are characterized and are observable if the intermediate insulating layer is thin enough. The coupling length of the $\mathrm{Ag} / \mathrm{TiO}_{2}$ RCSP mode with the $\mathrm{SiO}_{2}$ layer in between is less than $500 \mathrm{~nm}$. Therefore, a multicolored infrared emitter can be fabricated by clipping materials of different dielectric constants between two Ag films.

The authors would like to thank the National Science Council of Taiwan, Republic of China for financially supporting this research under Contract No. NSC 94-2215-E002-042.

${ }^{1}$ H. F. Ghaemi, Tineke Thio, D. E. Grupp, T. W. Ebbesen, and H. J. Lezec, Phys. Rev. B 58, 6779 (1998).

${ }^{2}$ T. W. Ebbesen, H. J. Lezec, H. F. Ghaemi, T. Thio, and P. A. Wolff, Nature (London) 391, 667 (1998).

${ }^{3}$ Kevin A. Tetz, Rostislav Rokitski, Maziar Nezhad, and Yeshaiahu Fainman, Appl. Phys. Lett. 86, 111110 (2005).

${ }^{4}$ Shaun A. Williams, Amanda D. Stafford, Trisha M. Rogers, Sarah R. Bishop, and James V. Coe, Appl. Phys. Lett. 85, 1472 (2004).

${ }^{5}$ Sri Priya Sundararajan, Jennifer Marie Steele, and Naomi J. Halas, Appl. Phys. Lett. 88, 063115 (2006).

${ }^{6}$ Tae-In Jeon and D. Grischkowsky, Appl. Phys. Lett. 88, 061113 (2006).

${ }^{7}$ J. W. Lee, M. A. Seo, D. S. Kim, S. C. Jeoung, Ch. Lienau, J. H. Kang, and Q.-Han Park, Appl. Phys. Lett. 88, 071114 (2006).

${ }^{8}$ Shaum M. Williams, Amanda D. Stafford, Kenneth R. Rodriguez, Trisha M. Rogers, and James V. Coe, J. Phys. Chem. B 107, 11871 (2003).

${ }^{9}$ Shaun M. Williams, Amanda D. Stafford, Trisha M. Rogers, Sarah R. Bishop, and James V. Coe, Appl. Phys. Lett. 85, 1472 (2004).

${ }^{10}$ Y.-H. Ye and Jia-Yu Zhang, Appl. Phys. Lett. 84, 2977 (2004).

${ }^{11}$ Q. Cao and P. Lalanne, Phys. Rev. Lett. 88, 057403 (2002).

${ }^{12}$ Y. H. Ye and J. Y. Zhang, Opt. Lett. 30, 1521 (2005).

${ }^{13}$ M. U. Pralle, N. Moelders, M. P. McNeal, I. Puscasu, A. C. Greenwald, J. T. Daly, E. A. Johnson, T. George, D. S. Choi, I. El-Kady, and R. Biswas, Appl. Phys. Lett. 81, 4685 (2002).

${ }^{14}$ T. H. Chuang, M. W. Tsai, Y. T. Chang, and S. C. Lee, Appl. Phys. Lett. 89, 033120 (2006).

${ }^{15}$ M. A. Ordal, L. L. Long, R. J. Bell, S. E. Bell, R. R. Bell, R. W. Alexander, Jr., and C. A. Ward, Appl. Opt. 22, 1099 (1983).

${ }^{16}$ Dawn K. Gifford and Dennis G. Hall, Appl. Phys. Lett. 80, 3679 (2002). 